14 Bianchi MC. Magnetic resonance angiography vs digital angiography in surgical selection of carotid stenosis. Nuova Rivista Di Neurologi 1995;5:229-34.

15 Dadachanji MC, Shroff MM, Modi D, Jankharia BG. Comparison of MR angiography with contrast angiography for the diagnosis of carotid artery stenosis. J Assoc Physicians India 1995;43:92-5.

16 Drevet D, Russier S, Age B, Lepine PM, Zabot JM, Joffre P. Study of atheromatous stenoses of carotid bifurcations by Doppler ultrasound, spiral angio-MRI, magnetic resonance angiography and comparison with arteriography. J Radiol 1997;78:1271-7.

17 Fellner C, Strotzer M, Fraunhofer S, Held P, Spies V, Seitz J, et al. MR angiography of the supra-aortic arteries using a dedicated head and neck coil: image quality and assessment of stenoses. Neuroradiology 1997;39:763-71

18 Huston J, Lewis BD, Wiebers DO, Meyer FB, Riederer SJ, Weaver AL. Carotid artery: prospective blinded comparison of two-dimensional time-of-flight MR angiography with conventional angiography and duplex US. Radiology 1993;186:339-44.

19 Kido DK, Panzer RJ, Szumowski J, Hollander J, Ketonen LM, Monajati A, et al. Clinical evaluation of stenosis of the carotid bifurcation with magnetic resonance angiographic techniques. Arch Neurol 1991;48:484-9.

20 Laster REJ, Acker JD, Halford HH, Nauert TC. Assessment of MR angiography versus arteriography for evaluation of cervical carotid bifurcation disease. Am J Neuroradiol 1993; 14:681-8.

21 Link J, Brinkmann G, Steffens JC, Graessner J, Muller-Hulsbeck S, Helle M. MR angiography of the carotid arteries using $3 \mathrm{D}$ TOF technique with sagittal double-volume acquisition using a new head-neck coil. Rofo For schr Geb Rontgenstr Neuen Bildgeb Verfahr 1996;165:544-50.

22 Litt AW, Eidelman EM, Pinto RS, Riles TS, McLachlan SJ, Schwartzenberg $\mathrm{S}$, et al. Diagnosis of carotid artery stenosis: comparison of 2DFT time-offlight MR angiography with contrast angiography in 50 patients. Am J Neuroradiol 1991;12:149-54

23 Magarelli N, Scarabino T, Simeone AL, Florio F, Carriero A, Salvolini U, et al. Carotid stenosis: a comparison between MR and spiral CT angiography. Neuroradiology 1998;40:367-73.

24 Martinat P, Leclerc X, Gauvrit JY, Giboreau F, Pruvo JP. Contribution of fast-sequence three-dimensional MRI angiography with Gadolinium injection in the evaluation of supra-aortic vessels. J Radiol 1998;79:67380 .

25 Mattle HP, Kent KC, Edelman RR, Atkinson DJ, Skillman JJ. Evaluation of the extracranial carotid arteries: correlation of magnetic resonance angiography, duplex ultrasonography, and conventional angiography. Vasc Surg 1991;13:838-44.

26 Nicholas GG, Osborne MA, Jaffe JW, Reed JF. Carotid artery stenosis: preoperative noninvasive evaluation in a community hospital. J Vasc Surg 1995;22:9-16.
27 Ozaki CK, Irwin PB, Flynn TC, Huber TS, Seeger JM. Surgical decision making for carotid endarterectomy and contemporary magnetic resonance angiography. Am J Surg 1999;178:182-4.

28 Pavone P, Catalano C, Di Girolamo M, Albertini PG, Marsili L, Passariello R. Angiography with magnetic resonance of the carotid arteries. Evaluation of clinical results obtained with low magnetic field equipment. Radiol Med (Torino) 1993;86:579-86.

29 Polak JF, Bajakian RL, O'Leary DH, Anderson MR, Donaldson MC, Jolesz FA. Detection of internal carotid artery stenosis: comparison of MR angiography, color Doppler sonography, and arteriography. Radiology 1992;182:35-40.

30 Remonda L, Heid O, Schroth G. Carotid artery stenosis, occlusion, and pseudo-occlusion: first-pass, gadolinium-enhanced, three-dimensional MR angiography - preliminary study. Radiology 1998;209:95-102.

31 Riles TS, Eidelman EM, Litt AW, Pinto RS, Oldford F, Schwartzenberg GW. Comparison of magnetic resonance angiography, conventional angiography, and duplex scanning. Stroke 1992;23:341-6.

32 Sardanelli F, Zandrino F, Parodi RC, De Caro G. MR angiography of internal carotid arteries: breath-hold Gd-enhanced 3D fast imaging with steady-state precession versus unenhanced 2D and 3D time-of-flight techniques. J Comput Assist Tomogr 1999;23:208-15.

33 Scarabino T, Carriero A, Magarelli N, Florio F, Giannatempo GM, Bonomo L, et al. MR angiography in carotid stenosis: a comparison of three techniques. Eur J Radiol 1998;28:117-25.

34 Scarabino T, Carriero A, Giannatempo GM, Marano R, De Matthaeis P, Bonomo L, et al. Contrast-enhanced MR angiography (CE MRA) in the study of the carotid stenosis: comparison with digital subtraction angiography (DSA). J Neuroradiologie 1999;26:87-91.

35 Sitzer M, Furst G, Fischer H, Siebler M, Fehlings T, Kleinschmidt A, et al. Between-method correlation in quantifying internal carotid stenosis. Stroke 1993;24:1513-8.

36 Turnipseed WD, Kennell TW, Turski PA, Acher CW, Hoch JR. Magnetic resonance angiography and duplex imaging: noninvasive tests for selecting symptomatic carotid endarterectomy candidates. Surgery $1993 ; 114: 643-8$

37 Uehara T, Tabuchi M, Ohsumi Y, Yoneda Y, Mori E. Usefulness of 3-dimensional time-of-flight mr-angiography for evaluation of carotidartery bifurcation stenosis. Cerebrovasc Dis 1995:5:199-203.

38 Wilkerson DK, Keller I, Mezrich R, Schroder WB, Sebok D, Gronlund J, et al. The comparative evaluation of three-dimensional magnetic resonance for carotid artery disease.J Vasc Surg 1991;14:803-9.

39 Young GR, Humphrey PR, Shaw MD, Nixon TE, Smith ET. Comparison of magnetic resonance angiography, duplex ultrasound, and digital subtraction angiography in assessment of extracranial internal carotid artery stenosis. J Neurol Neurosurg Psychiatry 1994;57:1466-78.

40 Bamford J. Risk stratification and carotid surgery: new technology but old trials. Brain 2001;124:455-6.

(Accepted 12 October 2001)

\title{
Time trends in survival and readmission following coronary artery bypass grafting in Scotland, 1981-96: retrospective observational study
}

\author{
J P Pell, K MacIntyre, D Walsh, S Capewell, J J V McMurray, J W T Chalmers, J H Boyd, \\ A R Finlayson, S Stewart, A D Redpath
}

Improvements in coronary revascularisation techniques and an increase in the use of percutaneous interventions ${ }^{1}$ have led to a rise in the number of coronary artery bypass grafting operations in older patients with more severe cardiac disease and worse comorbidity and who have previously undergone revascularisation procedures. ${ }^{23}$ Advances in surgical and anaesthetic techniques have prevented a worsening risk profile from being translated into an increase in perioperative deaths. ${ }^{23}$ The aim of our study was to examine time trends in major outcomes up to two years after coronary artery bypass grafting.

\section{Participants, methods, and results}

We used the Scottish morbidity record (SMR1) system to identify all operations for coronary artery bypass grafting performed in Scottish NHS hospitals from
1981 to 1996 . We excluded operations that included other procedures. Information was obtained on age, sex, urgency of the operation, and Carstairs socioeconomic deprivation category derived from postcode of residence. ${ }^{4}$ Record linkage to subsequent SMR 1 and registrar general records provided follow up information on readmission, repeat procedures, and death, both inside and outside of hospital, up to two years after the operation.

The study cohort comprised 25229 coronary artery bypass operations; $19687(78 \%)$ were performed in men and $5542(22 \%)$ in women. The number of operations overall increased from 68 to 490 per million population per year (see table A on the $B M J$ 's website for details). The percentage of operations performed on patients aged over 65 increased from $2 \%$ to $30 \%$ in men $(7 / 289 v 582 / 1950$, $\mathrm{P}<0.0001)$ and from $16 \%$ to $45 \%$ in women $(10 / 61 v$
Department of Medical Cardiology, Glasgow Royal Infirmary University NHS Trust, Glasgow G32 2ER J P Pell homorary clinical senior lecturer continued over BMJ 2002;324:201-2

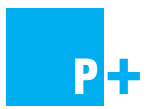

See the BMJ's website for more data on coronary artery grafts $1981-96$ 
Department of Public Health,

University of

Glasgow, Glasgow

G12 8RZ

K MacIntyre

research fellow

Department of

Medicine and

Therapeutics,

Gardiner Institute,

Western Infirmary,

Glasgow G11 6NT

JJ V McMurray

professor

S Stewart

research fellow

Information and

Statistics Division,

Common Services

Agency, Edinburgh

EH5 3SQ

D Walsh

senior health

information scientist

J W T Chalmers

consultant in public

health medicine

A D Redpath

statistician

J H Boyd

medical record linkage

manager

A R Finlayson

senior health

information scientist

Department of

Public Health,

University of

Liverpool,

Liverpool L69 3GB

S Capewell

professor

Correspondence to:

J Pell, Department

of Public Health,

Greater Glasgow

Health Board,

Glasgow G3 8YU

jill.pell@gghb.scot

nhs.uk

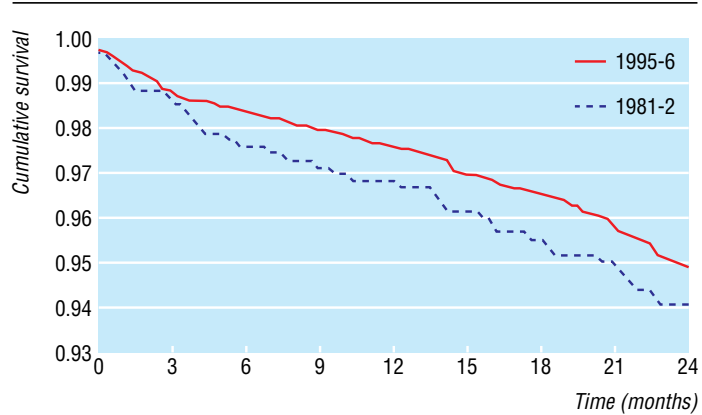

Age adjusted cumulative survival in men up to two years after coronary artery bypass grafting in 1981-2 and 1995-6

266/586, $\mathrm{P}<0.0001)$. No significant time trends in deprivation category or urgency were found. After adjustment for age in a Cox proportional hazards model, the risk of all cause mortality up to two years after the operation significantly declined in men over the study period (figure; see equivalent graph for women on website). Readmission for a principal cause of ischaemic heart disease also declined in men over the period $(\mathrm{P}<0.0001)$, whereas repeat coronary angiography increased ( $\mathrm{P}<0.0001$; see table $\mathrm{B}$ on website). There was no obvious trend in repeat coronary revascularisation procedures. Similar time trends were seen in women, but only the time trend in repeat coronary angiography reached significance $(\mathrm{P}<0.0001)$.

\section{Comment}

During 1981-96 the risk of death within two years of coronary artery bypass grafting and the need for readmission decreased significantly in men after data had been adjusted for age. The age of patients undergoing coronary artery bypass grafting has significantly increased; this agrees with previous studies. ${ }^{235}$ These improvements are likely to reflect developments in surgical technique, such as increased use of internal mam- mary artery grafts and of secondary prevention..$^{35}$ The failure of the results to reach statistical significance in women may simply reflect the fact that fewer procedures are carried out in women. The number of repeat coronary angiography procedures increased significantly in both sexes. However, the number of readmissions for ischaemic heart disease declined and there were no obvious increases in repeat coronary revascularisation; thus the increase in repeat angiography is more likely to reflect a reduced threshold for investigation than deteriorating outcomes.

Because the study was based on routine data, we were unable to adjust for possible changes in comorbidity or severity of cardiac disease. However, studies from Europe, the Far East, and the United States have consistently shown worsening risk profiles in relation to both of these. ${ }^{235}$ Therefore, failure to adjust for these is likely to have led to an underestimate of the improvements made.

Contributors: SC had the idea of studying survival trends. JPP developed the idea, reformatted and analysed the data, produced the first draft and made the necessary revisions. DW extracted the linked SMR1/GRO data; JPP, ARF, and JHB helped with the extraction specification. KM helped with the analysis and produced the figures. All authors contributed to interpretation of the results, commented on the first draft, and approved the final version. JPP is the guarantor.

Funding: British Heart Foundation.

Competing interests: None declared.

1 Delacretaz E, Meier B. Use of coronary angioplasty, bypass surgery, and conservative therapy for treatment of coronary artery disease over the past decade. Eur Heart J 1998;19:1042-6.

2 Haraphongse M, Na-Ayudhya RK, Teo KK, Williams R, Bay KS, Gelfand $\mathrm{E}$, et al. The changing clinical profile of coronary artery bypass graft patients, 1970-89. Can J Cardiol 1994;10:71-6.

3 Nishioka H, Taniguchi S, Kawata T, Mizuguchi K, Kameda Y, Sakaguchi $\mathrm{H}$, et al. Impact of percutaneous transluminal coronary angioplasty on coronary bypass surgery-changes in the patient profile during the past decade. Jpn Circ J 1998;62:665-9.

4 Carstairs V, Morris R. Deprivation and health in Scotland. Aberdeen: Aberdeen University Press, 1991

5 Black N, Langham S, Petticrew M. Trends in the age and sex of patients undergoing coronary revascularisation in the United Kingdom 1987-93. Br Heart J 1994;72:317-20.

(Accepted 25 June 2001)

\section{Endpiece \\ Letter to Georgiana Morpeth, 16 February 1820}

Dear Georgiana,

Nobody has suffered more from low spirits than I have-so I feel for you. Here are my prescriptions.

1st Live as well as you dare.

2nd Go into the shower-bath with a small quantity of water at a temperature low enough to give you a slight sensation of cold.

3rd Amusing books.

4th Short views of human life-not further than dinner or tea.

5 th Be as busy as you can.

6th See as much as you can of those friends who respect and like you.

7th And of those acquaintances who amuse you.

8th Make no secret of low spirits to your friends, but talk of them freely-they are always worse for dignified concealment.

9th Attend to the effects tea and coffee produce upon you.

10th Compare your lot with that of other people.

11th Don't expect too much from human life-a sorry business at the best. 12th Avoid poetry, dramatic representations (except comedy), music, serious novels, melancholy sentimental people, and every thing likely to excite feeling or emotion not ending in active benevolence.

13th Do good, and endeavour to please everybody of every degree.

14th Be as much as you can in the open air without fatigue.

15th Make the room where you commonly sit, gay and pleasant. 16th Struggle by little and little against idleness.

17th Don't be too severe upon yourself, or underrate yourself, but do yourself justice.

18th Keep good blazing fires.

19th Be firm and constant in the exercise of rational religion. 20th Believe me, dear Georgiana, your devoted servant, Sydney Smith

From Auden WH, ed. Selected writings of Sydney Smith. London: Faber and Faber, 1967 